\title{
PRACTICAL ASPECTS OF EARTHING
}

$\mathrm{I}_{\mathrm{com}}^{\mathrm{N}}$ the October issue of the Journal of the Institution of Electrical Engineers the important joint paper compiled by E. Fawssett, H. W. Grimmitt, G. F. Shotter and Dr. H. G. Taylor, on practical aspects of earthing, is published in full, together with the relevant discussion of the Transmission Section.

Particular attention is given to the methods of earthing the networks of supply stations so as to prevent dangerous high potentials occurring at any point. According to the definition given in the Electricity Supply Regulations, "connected with earth" means connected with the general mass of earth in such a manner as will ensure at all times an immediate and safe discharge of energy. The authors say that it is sometimes found that it is difficult to make a connexion with the general mass of earth in such a way as will ensure at all times a safe discharge of energy, depending as it does on the conductivity of the soil and the position of lakes, rivers, etc., in the neighbourhood.

In the discussion, Mr. J. F. Shipley appreciates the authors' suggestion that engineers should use geological drift maps, but points out that they have to be used with care as they are always made on a very large scale. With regard to the subject of rainfall, he said that in Great Britain it is very satisfactory from the point of view of earthing; there is plenty of it all the year round but not too much. Mr. Shipley has had experience of countries where the annual local rainfall is 400 inches and it nearly all falls within two or three months; the rain is so heavy that it sometimes completely washes the earth connexion away. The rain water is itself of very low conductivity, and as it falls in such quantity it acts as a leaching agent and washes all the conducting salts out of the soil, so that although the soil is soaked with the water in the wet season, it is still a bad conductor.

Figures are quoted bearing on this point. The condensate in a modern turbo-generating station has a conductivity figure (the reciprocal of megohms per $\mathrm{cm}$. cube) of about 2 . London rain water has a conductivity figure of about 390, and Glasgow water of about 120. Manchester water, one of the softest on record, has a conductivity figure of 48 , and sea water a figure of 50,000 . In one case Mr. Shipley found the conductivity of the water to be of the order 18; this was after six months storage in a reservoir and a five or six mile journey along a river bed. $\mathrm{He}$ estimates that the original conductivity figure was about 10. When, therefore, heavy rainfall occurs in atmospheres that are comparatively free from dust and pollution, the rain water is an almost perfect insulating material. He found this out in a practical way by trying to test a $6 \cdot 6 \mathrm{kv}$. alternator on a testing tank. Ordinary water from the hillside was used, and it was found that with electrodes in water three feet apart there was not the slightest sign of current passing between them.

A case was also described where considerable damage was done by lightning to a lead-covered cable in the dry climate of South Africa. The cores were repeatedly damaged by discharges within the cable which coincided with lightning strokes striking the ground some distance away. In Great Britain we are accustomed to think that if lead-sheathed cable is buried in the earth, the conductor inside is safe from external discharges, but this incident shows that this is not the case. Owing to the dryness and high resistivity of the soil, the earthing secured by the cable being buried was insufficient; and the cable is now being additionally earthed at intervals by pipe-earths.

Mr. P. B. Frost pointed out that telephone cables are damaged by lightning in Great Britain as well as in Africa. In one case, a long main underground cable not connected in any way with overhead lines developed about ten faults distributed over some miles, due to lightning discharge between the sheath and the conductors.

\section{THE ACOUSTIC AIR-JET GENERATOR}

$I^{N}$ 1916, Prof. Hartmann, of Copenhagen, while exploring with a Pitot tube the distribution of total head in a high-speed jet of air, observed that the pressure along the axis of the jet underwent a cyclic variation with its distance from the discharge nozzle. This so-called Pitot curve, shaped like a sine wave of diminishing amplitude, comprises successive wave-lengths along which the pressure is alternately falling and rising. It was found that the intervals of rising pressure were unstable. When, for example, the pressure over these regions was explored with a wide Pitot tube, unstable readings were obtained, indicating that the air in the jet alternately entered and was discharged from the tube with a regular frequency. The same phenomena occurred when the open end of a hollow vessel or oscillator' was mounted in a rising pressure of the air jet, the result with this arrangement being the production of vigorous sound waves varying in frequency according with the volume of the oscillator and the size of its open end.

In Engineering of October 18, it is stated that Prof. Hartmann has spent several years in developing an acoustic sound generator based on this principle. In his researches he has been assisted by three other physicists and supported financially by Danish endowments. The generator was described and demonstrated by Prof. Hartmann at the Blackpool meeting in 1936 of the British Association.

The final account of Prof. Hartmann's work, now issued in English as No. 4 of the Ingeniorvidenskabelige Skrifter (Akademiet for de Tekniske Videnskaber ok Dansk Ingeniörforening), covers a good deal of experimental research hitherto unpublished 
in English, and presents complete data and theoretical analyses immediately useful to research workers in acoustics.

It appears that the fundamentally scientific aspects of the generator and its mode of operation have been adequately covered. Except for its obvious utility as a source of controllable sound for acoustic research, the authors in this paper put forward no specific suggestions for applying it usefully in engineering or other industries, although in previous accounts they have discussed its possibilities for precipitating smoke and dust in the atmosphere and for producing supersonic vibrations which might be employed for testing the quality of materials. Its potentialities as a means of communication and for transmitting supersonic energy through the air will also warrant the closest consideration. But over the audible range of frequency the Hartmann generator is faced with the opposition of a host of already firmly established competitors. The article concludes by saying that the reticence of the inventors on new ways and means of augmenting the sufferings of a noise-tormented world has much to com. mend it.

\section{FEMALE SEX HORMONES*}

\section{The Ovarian Follicular Hormones}

\section{By PRop. E. A. DoIsY, St. Louts University}

$\mathrm{T}$

HE ovarian follicular hormone, manufactured in the ripening follicle of the ovary, is one of the so-called cestrogenic hormones-chemicals which cause the female to exhibit mating behaviour. In the human and in other animals the cestrogenic hormones prepare the lining of the uterus for the reception of the fertilized egg, stimulate the development of mammary glands, and at the time of birth activate the womb.

Of more practical interest, however, are the remarkable therapeutic benefits obtained with these hormones in a variety of conditions. Some of the most striking results have been achieved in ameliorating the effects of the menopause and in correcting various disorders associated with the sex cycle.

Doisy and associates were the first to isolate an œstrogenic hormone in crystalline form in 1929. The substance, which was called theelin, was extracted from human urine. Later it was isolated from numerous other sources.

While theelin is produced in the ovaries and, during pregnancy, in the placenta, the hormone is much more easily extracted from the urine. The first yield from this source was only $1.5 \mathrm{mgm}$. It was not until 1935 that Doisy, MacCorquodale and Thayer were able to extract the cstrogenic hormone from the organs themselves, and in this work they used four tons of ovaries from sows. It took two years to obtain enough of the pure compound for thorough chemical and biological characterization, for the concentration existing in the swine ovary was only $6 \mathrm{mgm}$. per ton, or about one part in 150,000,000. The pure material was named $\alpha$-dihydrotheelin, differing from theelin only in the addition of two more hydrogen atoms. In obtaining the substance from human material, one worker used 702 full term placentas, which were obtained at childbirth and which weighed altogether a half ton.

Prof. Carl Bachman synthesized theelin in 1940 from simple organic compounds, an achievement which may be described as one of the outstanding accomplishments in the sex hormone field. This and other cestrogenic hormones prepared synthetically are so much cheaper than the products obtained by necessarily tedius extraction of the natural material that the therapeutic use of the compounds is increasing.

* Substance of a symposium held at the Bicentennial Conference of the University of Pennsylvania on September 18.
Toxic effects are, however, reported by some physicians using synthetic hormones, and it is to be hoped that chenaists may be able to remove the toxicity without producing loss of the cstrogenic property.

\section{The Gonadotropic Hormones}

By Prof. P. E. Smith, Columbia University

Intensive study of the interaction between these particular members of the endocrine system, namely, the pituitary and the sex glands, began about thirteen years ago, when it was discovered that the sex glands were not independently functioning organs but were dependent upon some unknown but essential $X$-substance for their maintenance. It was next revealed that this $X$-substance which stimulated the sex glands was supplied by the anterior lobe of the pituitary gland (also known as the anterior hypophysis).

In rapid succession three rich sources of gonadstimulating (gonadotropic) substances were found. One was the urine of pregnant women. One was the urine of women who had had their ovaries removed or who had passed the menopause. The third was the blood serum of pregnant mares. The effects of these substances were observed not only by clinical use in various disturbances of the normal cyclical behaviour of the female sex glands but also in laboratory tests upon animals-principally rats and monkeys-the pituitary glands of which had been removed.

One of the early complications in this study was the fact that all species do not react identically or even similarly. Also extracts of pituitary glands from various species of animals gave different responses on one species of test animal. These differences early gave rise to the concept that the somewhat different effects were due to the presence of more than one gonadotropic hormone in the pituitary.

In 1931, Dr. Frederick L. Hisaw and Dr. H. L. Fevold, of Harvard, announced they had obtained two gonadotropic fractions from the pituitary gland of the sheep. One they called the FSH (follicle stimulating hormone) and the other became known as the LH (luteinizing hormone). According to their theory, which was supported by several other workers, the FSH causes growth of the follicle in the ovary. The œestrogenic hormone of the follicle in turn influences the pituitary and causes secretion of the $L H$. When the two pituitary hormones are in proper 